\title{
Physical Characterisation of an Alginate/Lysozyme Nano-Laminate Coating and Its Evaluation on 'Coalho' Cheese Shelf Life
}

\author{
Bartolomeu G. de S. Medeiros • Marthyna P. Souza • \\ Ana C. Pinheiro - Ana I. Bourbon • \\ Miguel A. Cerqueira - António A. Vicente • \\ Maria G. Carneiro-da-Cunha
}

Received: 5 January 2013 / Accepted: 18 March 2013 /Published online: 4 April 2013

(C) Springer Science+Business Media New York 2013

\begin{abstract}
This work aimed at the characterisation of a nanolaminate coating produced by the layer-by-layer methodology and its evaluation on the preservation of 'Coalho' cheese. Initially, five alternate layers of alginate and lysozyme were assembled in an aminolysed/charged polyethylene terephthalate (A/C PET) and physically characterised by UV/VIS spectroscopy, contact angle, water vapour (WVTR) and oxygen (OTR) transmission rates and scanning electron microscopy. Afterwards, the same methodology was used to apply the nano-laminate coating in 'Coalho' cheese and its shelf life was evaluated during 20 days in terms of mass loss, $\mathrm{pH}$, lipid peroxidation, titratable acidity and microbial count. UV/VIS spectroscopy and contact angle analyses confirmed the layers' deposition and the successful assembly of nano-laminate coating on A/C PET surface. The coating presented WVTR and OTR values of $1.03 \times 10^{-3}$ and $1.28 \times$ $10^{-4} \mathrm{~g} \mathrm{~m}^{-2} \mathrm{~s}^{-1}$, respectively. After 20 days, coated cheese showed lower values of mass loss, $\mathrm{pH}$, lipidic peroxidation, microorganisms' proliferation and higher titratable acidity in
\end{abstract}

\footnotetext{
B. G. de S. Medeiros • A. C. Pinheiro - A. I. Bourbon •

M. A. Cerqueira $(\square) \cdot$ A. A. Vicente $(\square)$

IBB-Institute for Biotechnology and Bioengineering,

Centre of Biological Engineering, Universidade do Minho,

Campus de Gualtar,

4710-057 Braga, Portugal

e-mail: miguelcerqueira@deb.uminho.pt

e-mail: avicente@deb.uminho.pt

B. G. de S. Medeiros • M. P. Souza •

M. G. Carneiro-da-Cunha $(\bowtie)$

Departamento de Bioquímica, Laboratório de Imunopatologia

Keizo Asami (LIKA), Universidade Federal de Pernambuco

(UFPE), Av. Prof. Moraes Rego, s/n, Cidade Universitária,

CEP 50670-420 Recife, Pernambuco, Brazil

e-mail: mgcc@ufpe.br
}

comparison with uncoated cheese. These results suggest that gas barrier and antibacterial properties of alginate/lysozyme nanocoating can be used to extend the shelf life of 'Coalho' cheese.

Keywords Nanomultilayers $\cdot$ Barrier properties · Antimicrobial $\cdot$ Shelf life $\cdot$ Cheese

\section{Introduction}

One of the main challenges in food industry is the production of food of high quality, keeping quality and safety for a longer period of time. One of the promising ways to achieve this goal is the application of edible coatings on food surface. Edible coatings are composed by natural polymers, which with functions such as selective gas barrier (Cerqueira et al. 2009) and antimicrobial action (Rhim et al. 2006; Martins et al. 2010) can improve the quality and safety of foods. Nowadays, one of the challenges with the application of edible coatings is the utilisation of nanotechnology in order to overcome some problems related to high water vapour permeability and poor mechanical properties of edible coatings in comparison with synthetic materials (Neethirajan and Jayas 2011). Some advantages when these coatings are at the nano-scale are: high stability on the substrate surface, facility of preparation (Peng et al. 2001) and lower concentration of materials required (Hinrichsen et al. 2003). However, few studies have explored the application of edible coatings on foods at a nano scale level.

The construction of nano-laminate coatings can be achieved by the layer-by-layer (LbL) deposition technique, which 
consists in the electrostatic self-assembly deposition of successive layers on a substrate surface, mainly due to electrostatic forces (Decher 2003). They have been applied in various fields, such as medicine (Zhong et al. 2007) and food industry (Medeiros et al. 2012a, b). LbL has been suggested to be suitable to obtain nano-laminate coatings based on natural polymers (Jiang and Li 2009; Carneiro-da-Cunha et al. 2010; Pinheiro et al. 2012).

The material used for the construction of a nanolaminate coating for food should be electrostatically charged and preferentially with functional properties of interest, such as antimicrobial, antioxidant and gas barrier properties. For this purpose, two biomolecules such as alginate and lyzozyme can be used. Alginate is a natural anionic polysaccharide that can be extracted from cell walls of marine brown seaweed. It is a linear binary copolymer that consists of $(1 \rightarrow 4)$-linked to $\beta$-Dmanuronic acid (M) and $\alpha$-L-guluronic acid residues $(\mathrm{G})$ (Saether et al. 2008). The sodium salt of alginic acid has been used by food industry to increase viscosity and as an emulsifier. Lysozyme is a protein extracted from chicken egg, which has good resistance to denaturation ( $\mathrm{Su}$ et al. 1998) presenting antibacterial property (Ibrahim et al. 2001).

The utilisation of nano-laminate coatings for food packaging has been tested on fruits (Medeiros et al. 2012a, b), however it was never tested on cheese. Cheese, a widely consumed product, is a complex food product that is mainly composed by casein, fat and water (Nussinovitch and Kampf 2000) that when sold unpackaged has a limited shelf life. The 'Coalho' cheese is one of the cheese varieties that have more economic and social importance in the Northwest region of Brazil (Borges et al. 2003; Perry 2004). 'Coalho' cheese is a semi-hard cheese usually ripened but also consumed fresh (FAO 1990; Ministério da Agricultura 1996), in which many studies have confirmed the presence of spoilage microorganisms, some of them being pathogenic (e.g. Staphylococcus aureus, Salmonella spp.) (Santana et al. 2008). In addition, quality and safety issues limit the marketing of this cheese, since it is considered a handmade cheese and most often from raw milk without the proper hygiene care (Borges et al. 2003). The considerable consumption and economic importance of this popular cheese in countries such Brazil confirm the importance of the study for new ways to ensure the quality and safety of this kind of product. In order to achieve that goal the, main objectives of this work were the characterisation of the nano-laminate coating of alginate/lysozyme through UV/VIS spectroscopy, contact angle, water vapour transmission rate (WVTR), oxygen transmission rate (OTR) and scanning electron microscopy (SEM) and the evaluation of mass loss, $\mathrm{pH}$, lipid peroxidation, titratable acidity and microbial count after their application in 'Coalho' cheese.

\section{Material and Methods}

\section{Material}

Polyethylene terephthalate (PET) films were obtained from Canson (France). Alginate was obtained from Manutex RSX (Kelco International, Ltd) and lysozyme from SigmaAldrich (USA). The 1,6-hexanediamine (98\%) was obtained from Aldrich (Germany) and propanol (99.8\%) from Sigma-Aldrich (USA). Lactic acid (90\%) and hydrochloric acid (37\%) were obtained from Merck (Germany). Ethanol (99.8 \%) and sodium hydroxide were obtained from Riedel-de Haën (Germany). Fresh commercial 'Coalho' cheese without any previous treatment was purchased at the open local market (Recife, Brazil) from the same batch and scale production, produced on the day before. Cheese samples were selected based on their uniformity, colour and apparent absence of damage and fungal infection.

Preparation and Characterisation of Nano-Laminate Coating

The nano-laminate coating was firstly assembled on aminolysed/charged PET (A/C PET) support film. Support aminolysis was carried out according to Carneiro-da-Cunha et al. (2010). Alginate (Algi) solution was prepared dissolving $0.2 \%(w / v)$ in distilled water under agitation, with a magnetic stirrer, at $200 \mathrm{rpm}$ for $2 \mathrm{~h}$ at $70{ }^{\circ} \mathrm{C}$ and after that for $22 \mathrm{~h}$ at $20^{\circ} \mathrm{C}$. Lysozyme (Lyso) solution was also prepared dissolving $0.2 \%(w / v)$ in distilled water under agitation at $200 \mathrm{rpm}$ for $2 \mathrm{~h}$ at $20{ }^{\circ} \mathrm{C}$. The $\mathrm{pH}$ of alginate and lysozyme solutions was adjusted to $\mathrm{pH} 7.0$ with a $1 \mathrm{M}$ $\mathrm{NaOH}$ solution and to $\mathrm{pH} 3.8$ with a $1 \mathrm{M}$ lactic acid solution, respectively.

$\mathrm{A} / \mathrm{C}$ PET support pieces with rectangular and circular shape of $0.8 \times 5.0 \mathrm{~cm}$ and $5.0-\mathrm{cm}$ diameter, respectively, were immersed into the Algi solution for $20 \mathrm{~min}$, subsequently rinsed with distilled water at the same $\mathrm{pH}$ (7.0) than Algi solution and dried during $1 \mathrm{~h}$ inside a chamber with a gentle nitrogen flow to speed up the drying process at $20{ }^{\circ} \mathrm{C}$ and $0 \% \mathrm{RH}$. This procedure was repeated with Lyso solution but in this case rinsing was carried out with distilled water at the same $\mathrm{pH}$ (3.8) of Lyso solution. This process was repeated with the alternate deposition of a total of five nanolayers. The obtained nano-laminate coating on $\mathrm{A} / \mathrm{C}$ PET support film with the sequence AlgiLyso-Algi-Lyso-Algi was finally maintained at $20 \pm 2{ }^{\circ} \mathrm{C}$ and $50 \pm 5 \%$ of relative humidity $(\mathrm{RH})$ provided by the laboratory air conditioning system, for further analyses (less than 5 days). The $\mathrm{pH}$ values of the solutions were chosen, considering the values of $\mathrm{p} K_{\mathrm{a}}$ and $\mathrm{p} I$ of alginate and lyzozyme, respectively, and the previous studies of Medeiros et al. (2012b) for lysozyme and Carneiro-daCunha et al. (2010) for alginate. 


\section{Zeta Potential}

The zeta potential of Algi and Lyso solutions was determined by dynamic light scattering (Zetasizer Nano ZS, Malvern Instruments, UK) to confirm both charge and magnitude of this parameter. Each sample was analysed in a disposable capillary cell (DTS1061) at $25^{\circ} \mathrm{C}$. Three true replicates were conducted, with three readings for each of them.

\section{Fourier Transform Infrared Spectroscopy}

The presence of amine groups on PET pieces' surface was detected by Fourier Transform Infrared Spectroscopy. Fourier transform infrared (FTIR) analyses were carried out with a Perkin Elmer 16 PC spectrometer (Perkin Elmerm, Boston, USA) equipped with an ATR probe in the wave number region of $650-4,000 \mathrm{~cm}^{-1}$ using 16 scans for each sample. Signal averages were obtained at a resolution of $4 \mathrm{~cm}^{-1}$. Two replicates were performed to each sample.

\section{UV-Vis Spectroscopy}

To follow the coating assembly onto support surface, UVvis analyses were carried out using a UV-vis spectrophotometer (Jasco 560, Germany). The absorbance of successive deposition of layers was measured at $266 \mathrm{~nm}$, after the deposition of each layer (and upon drying). Three replications of the measurements were taken.

\section{Contact Angle and Scanning Electron Microscopy Analysis}

The contact angles on original PET, A/C PET and on the subsequent five nanolayers' surface were measured in a contact angle meter (OCA 20, Dataphysics, Germany) by the sessile drop method (Newman and Kwok 1999). A 2- $\mu \mathrm{L}$ droplet of ultra pure water was placed on the horizontal surface with a $500-\mu \mathrm{L}$ syringe (Hamilton, Switzerland) with a needle of $0.75-\mathrm{mm}$ diameter. Measurements were made at $15 \mathrm{~s}$ and for each surface three samples were used. For each sample, ten contact angle measurements were carried out at $18 \pm 0.3{ }^{\circ} \mathrm{C}$.

The surface morphology of the studied material was examined using a scanning electron microscope (Nova 130 NanoSEM 200, the Netherlands) with an accelerating voltage from 10 to $15 \mathrm{kV}$. Before analysis all samples were mounted on aluminium stubs using carbon adhesive tape and sputter-coated with gold (thickness of about $10 \mathrm{~nm}$ ).

\section{Water Vapour Transmission Rate Measurement}

WVTR was carried out based on ASTM E96-92 method, with some modifications (Casariego et al. 2009). The A/C PET support and the subsequent nanolayers were sealed at the top of a permeation cell containing $55 \mathrm{ml}$ of distilled water $\left(100 \% \mathrm{RH}\right.$, vapour pressure of $2,337 \mathrm{~Pa}$ at $\left.20{ }^{\circ} \mathrm{C}\right)$. The supports were placed in a desiccator at $20{ }^{\circ} \mathrm{C}$ and $0 \%$ of $\mathrm{RH}$, containing silica. The cells were weighted during $10 \mathrm{~h}$ at time intervals of $2 \mathrm{~h}$. The slope of mass loss versus time was achieved by linear regression. Three replicates were obtained for each sample and WVTR of five nanolayers (Algi-Lyso-Algi-Lyso-Algi) was determined by the following equation:

$$
W V T R_{b}=\frac{1}{\left(\frac{1}{W V T R_{T}}\right)-\left(\frac{1}{W V T R_{a}}\right)}
$$

where $a, b$ and $T$ correspond, respectively, to: (a) A/C PET support, $(b)$ five nanolayers (Algi-Lyso-Algi-Lyso-Algi) and $(T)$ the resulting A/C PET support coated with five nanolayers (A/C PET-Algi-Lyso-Algi-Lyso-Algi).

\section{Oxygen Transmission Rate Measurement}

OTR was determined according to ASTM D 3985-02 (2002) method. Samples were sealed between two chambers, each one with two channels. To keep the pressure constant in the compartment, in the lower chamber, the $\mathrm{O}_{2}$ was supplied at controlled flow rate by a gas flow meter (J \& W Scientific, ADM 2000, USA) and the other chamber, also under controlled flow, was purged by a stream of nitrogen. The nitrogen acted as a carrier for the $\mathrm{O}_{2}$. The flow leaving this chamber was connected to an $\mathrm{O}_{2}$ sensor (Mettler Toledo- $-\mathrm{O}_{2} 4100$, Switzerland), which measured the $\mathrm{O}_{2}$ concentration in that flow on-line. The flows of the two chambers were connected to a manometer to ensure the equality of pressures (both at $1 \mathrm{~atm}$ ) between both compartments. As the $\mathrm{O}_{2}$ was carried continuously by the nitrogen flow, it was considered that the partial pressure of $\mathrm{O}_{2}$ in the upper compartment is null, therefore $\Delta P$ is equal to $1 \mathrm{~atm}$. Three replicates were obtained for each sample and the OTR for the five nanolayers (AlgiLyso-Algi-Lyso-Algi) was determined with the following equation:

$O T R_{b}=\frac{1}{\left(\frac{1}{O T R_{T}}\right)-\left(\frac{1}{O T R_{a}}\right)}$

where $a, b$ and $T$ correspond, respectively, to: $a$, the A/C PET support; $b$, five nanolayers (Algi-Lyso-Algi-Lyso-Algi); and $T$ the resulting A/C PET support coated with five nanolayers (A/C PET-Algi-Lyso-Algi-Lyso-Algi.

Cheese Coating and Shelf Life Evaluation

Raw cow 'Coalho' cheese was cut in circular pieces with $27 \mathrm{~cm}$ of diameter, washed with running water, left to dry 
(during $20 \mathrm{~min}$ at the temperature of $25{ }^{\circ} \mathrm{C}$ and $\mathrm{RH}$ of $66.5 \%$ ) and randomly divided into two groups of 18 samples each: control and test group. Coating solutions (Algi and Lyso) were applied on test group in a similar way as done on A/C PET surface. The immersion time of test group into each solution was of $5 \mathrm{~min}$. This immersion time was optimised in preliminary tests $(20,10$ and $5 \mathrm{~min})$. For the control group, distilled water with the respective $\mathrm{pH}$ of Algi $(\mathrm{pH}=7.0)$ and Lyso $(\mathrm{pH}=3.8)$ was used instead of the polyelectrolyte solutions used with test group. Afterwards, the cheese samples were placed into open plastic boxes and stored at $8{ }^{\circ} \mathrm{C}$ and $93 \% \mathrm{RH}$ (in a controlled temperature and humidity room). Over the 20 days of experimental period, physical-chemical and microbiological analyses were carried out at a time interval of 4 days, in triplicate for each sample.

\section{Mass Loss}

All cheese samples were individually weighted with a semiprecision balance (B-TEC-500, Brazil). The mass loss $(W)$ was determined with the following equation:

$W(\%)=\frac{\left(m_{i}-m_{t}\right)}{m_{t}} \cdot 100$

where $m_{i}$ is the initial weight and $m_{t}$ is the weight at time $t$.

\section{pH, Titratable Acidity and Lipid Peroxidation}

The $\mathrm{pH}$ value was determined using $5 \mathrm{~g}$ of cheese liquefied in a blender (Becken max mix II, Spain) with $50 \mathrm{~mL}$ of distilled water during $1 \mathrm{~min}$ through a $\mathrm{pH}$ meter (Instituto Adolf Lutz 1985). Afterwards, the same mixture was titrated with $0.1 \mathrm{~N} \mathrm{NaOH}$ solution to determine the titratable acidity (Instituto Adolf Lutz 1985). The results of titratable acidity were expressed as percentage $(w / w)$.

The oxidation of lipids was estimated using the thiobarbituric acid assay according to Kristensen et al. 1999. To $6 \mathrm{~g}$ of cheese, accurately weighted, were added $18 \mathrm{~mL}$ of $0.67 \%(w / v)$ thiobarbituric acid in $50 \%(v / v)$ acetic acid. The resulting mixture was homogenized using an Ultra Turrax homogenizer at 24,000 rpm (Jankel \& Kunkel IKA Labortechnik, Staufen, Germany) until the mixture appeared to be homogeneous. Six millilitres of the suspension were transferred to a test tube to which $3.5 \mathrm{~mL}$ of chloroform were added, followed by gentle mixing for $5 \mathrm{~min}$ and at $70 \mathrm{rpm}$ in an orbital incubator shaker TE-424 (Tecnal, Brazil) and, after that, centrifuged for $15 \mathrm{~min}$ at $754 \times g$. The aqueous phase was transferred to another test tube, which was placed into a water bath at $100{ }^{\circ} \mathrm{C}$ for $10 \mathrm{~min}$, followed by cooling with ice. The orange-red cyclohexanone supernatant was decanted and its absorbance was measured spectrophotometrically (UV-Visible Spectrophotometer, Smart Spec ${ }^{\mathrm{TM}} 3000$, Bio-Rad, United States) at $450 \mathrm{~nm}$. The results were expressed as absorbance units at $450 \mathrm{~nm} / \mathrm{g}$ of cheese.

\section{Microbiological Analyses}

Microbiological analyses were carried out by counting the total mesophilic and psychrotropic microorganisms according to the Portuguese standard NP 4405 (2002). Briefly, cheese samples $(1 \mathrm{~g})$ were collected in sterilised jars containing $9 \mathrm{~mL}$ of solution of $0.1 \%(w / v)$ peptone water in $0.9 \%(w / v) \mathrm{NaCl}$ and homogenized in aseptic conditions. One millilitre of each sample was transferred to each of two Petri dishes. For each inoculated dish, approximately $15 \mathrm{~mL}$ of Plate Count Agar (Vetec, Brazil) was added at $44-47^{\circ} \mathrm{C}$. The samples were mixed immediately after pouring by rotating the Petri dish sufficiently to obtain evenly dispersed colonies after incubation. After complete solidification, the plates were inverted and incubated at $30{ }^{\circ} \mathrm{C}$ for 3 days to evaluate total mesophilic microorganisms and kept at $8{ }^{\circ} \mathrm{C}$ for 10 days to evaluate total psychrotropic microorganisms. The results were expressed in log colonyforming units per gram.

\section{Visual Evaluation}

Visual evaluation of the cheese surface was carried out in order to confirm the microbiological contamination. Images were taken using a camera (Sony_Cyber-shot, USA).

\section{Statistical Analyses}

The statistical analyses were carried out using analysis of variance, comparisons between samples were analysed using Student's $t$ test. Differences were considered to be significant at $p<0.05$ (GraphPad Prism, version 6, 2012, USA).

\section{Results and Discussion}

Physical Characterisation of Polyelectrolyte Solutions and Nano-Laminate Coating

\section{Fourier Transform Infrared Spectroscopy}

FTIR spectroscopy was used to confirm the successfully aminolysis of PET surface. The presence of amino groups on the $\mathrm{A} / \mathrm{C}$ PET surface was confirmed by the presence of two peaks located at 1635 and at $1,557 \mathrm{~cm}^{-1}$, which are related to the amide I and amide II groups, respectively (results not shown) (Fu et al. 2005; Medeiros et. al. 2012a, b). 


\section{Zeta Potential}

The zeta potential value for alginate was found to be $-60.97 \pm$ $2.74 \mathrm{mV}$ at $\mathrm{pH} 7.0$, lower and oppositely charged in comparison with that found for lysozyme, $+29.27 \pm 3.18 \mathrm{mV}$ at $\mathrm{pH} 3.8$, enough condition to support the electrostatic selfassembly. The negative potential zeta value for alginate is explained by the free carboxyl groups present in its structure at $\mathrm{pH} 7.0$ (higher than its $\mathrm{p} K_{\mathrm{a}}$ that stands at 3.5) (Harnsilawat et al. 2006; Saravanan and Rao 2010). The positive zeta potential value for lysozyme is justified by the presence of amine groups at $\mathrm{pH} 3.8$ (lower than its isoelectric point that stands at 11.0) (Lvov et al. 1995; Satishkumar and Vertegel 2008). These values of zeta potential are similar to those found by Carneiro-da-Cunha et al. (2010) for alginate $(-62.13 \mathrm{mV}$ at $\mathrm{pH} 7.0)$ and Medeiros et al. (2012b) for lysozyme $(+25.67 \pm$ $2.27 \mathrm{mV}$ at $\mathrm{pH} 3.8$ ).

\section{UV-Vis Absorbance}

The assembly of the nano-laminate coating on the A/C PET support surface was followed by UV-vis spectroscopy analysis at $266 \mathrm{~nm}$ of A/C PET support and of the five successive alginate (Algi) and lysozyme (Lyso) layers after each deposition (Fig. 1). The absorbance value increases with the successive deposition of the five layers confirming the successful deposition of the layers. This behaviour is explained by the amount of alginate and lysozyme molecules adsorbed that causes an increase of the absorption value during the nano-laminate coating assembly on the A/C PET support surface. The same behaviour was observed by Wang et al. (2007) when nano-laminates composed by fibroin silk where built and led to an absorbance increase. Carneiro-da-Cunha et al. (2010) also found a successive increase of the absorbance value with the deposition of five nanolayers of alginate and chitosan on $\mathrm{A} / \mathrm{C}$ PET surface.

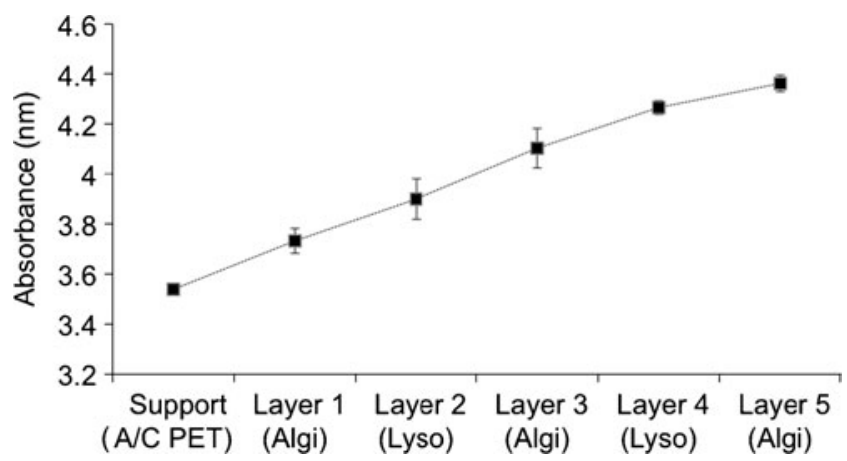

Fig. 1 UV-vis spectroscopy analysis at $266 \mathrm{~nm}$ of A/C PET support and after the adsorption of the five successive alginate (Algi) and lysozyme (Lyso) layers. Each data point is the average of three determinations and the error bars show the standard deviation
Contact Angle

Figure 2 shows the successive and alternate variation of the value of contact angle found to each successive outmost layer. It was found on Original PET surface a contact angle value of $76.2 \pm 2.0^{\circ}$, higher $(p<0.05)$ than the value of $65.4 \pm 2.4^{\circ}$ found for A/C PET surface. This difference confirms the aminolysis of original PET surface and simultaneously the hydrophobic nature of both. Similar results were observed by Medeiros et al. (2012a) and Carneiro-da-Cunha et al. (2010) that also found a greater hydrophobicity on the original PET surface than on the A/C PET surface. According to Durmaz et al. (2010), the hydrophobicity/hydrophilicity of a surface can be characterised by the contact angle measurement and also allows the confirmation of any chemical and physical change that can happen in a substrate surface.

The contact angle value found on outmost alginate layers surface ranged between $27.2 \pm 2.6^{\circ}$ and $33.7 \pm 3.0^{\circ}(p<0.05)$, disclosing its hydrophilic character (Zazouli et al. 2010), while on the outmost lysozyme layers surface it was found within the range from $50.4 \pm 7.0^{\circ}$ to $55.5 \pm 1.8^{\circ}(p<0.05)$ according to their moderate hydrophobic character. The contact angles with small magnitude were found on the surface of layers assembled at $\mathrm{pH} 7.0$ (Algi) and with great magnitude on the surface of layers assembled at $\mathrm{pH} 3.8$ (Lyso).

Figure 3 shows the five layers of the two polyelectrolytes, alginate and lysozyme captured by SEM, confirming the construction of the nanolayered film on the A/C PET surface.

\section{Water Vapour and Oxygen Transmission Rate (WVTR and OTR)}

The values of WVTR and OTR for the aminolyzed/charged PET were found to be $3.50 \pm 0.53 \times 10^{-4}$ and $2.47 \pm 0.03 \times$

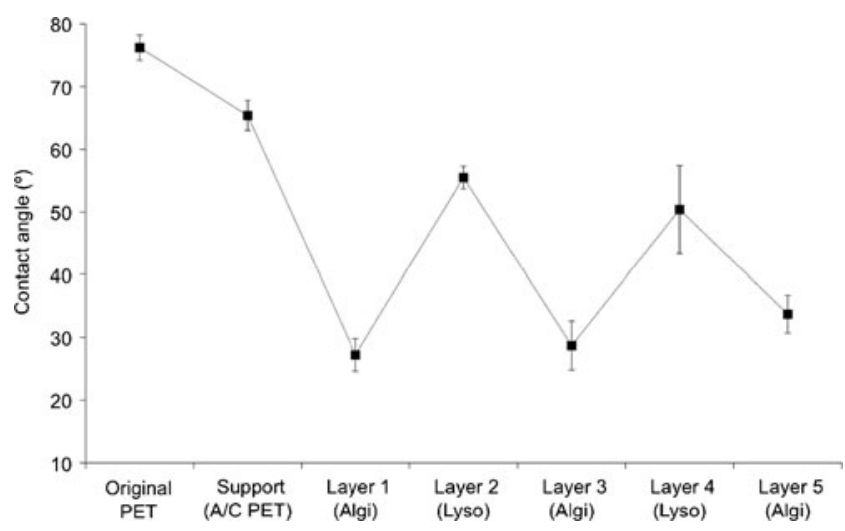

Fig. 2 Values of contact angles measured on Original PET, on A/C PET support and on each of the five successive layers containing alginate (Algi) and lysozyme (Lyso) after $15 \mathrm{~s}$ of droplet application. Each data point is the average of thirty measurements and the error bars show the standard deviation 
Fig. 3 Scanning electron microscopy images of surface morphology of the A/C PET nanomultilayer coating a thickness of the nanolayer, $\mathbf{b}$ nanolayers (magnification $50,000 \times$ and scale bar $1 \mu \mathrm{m})$
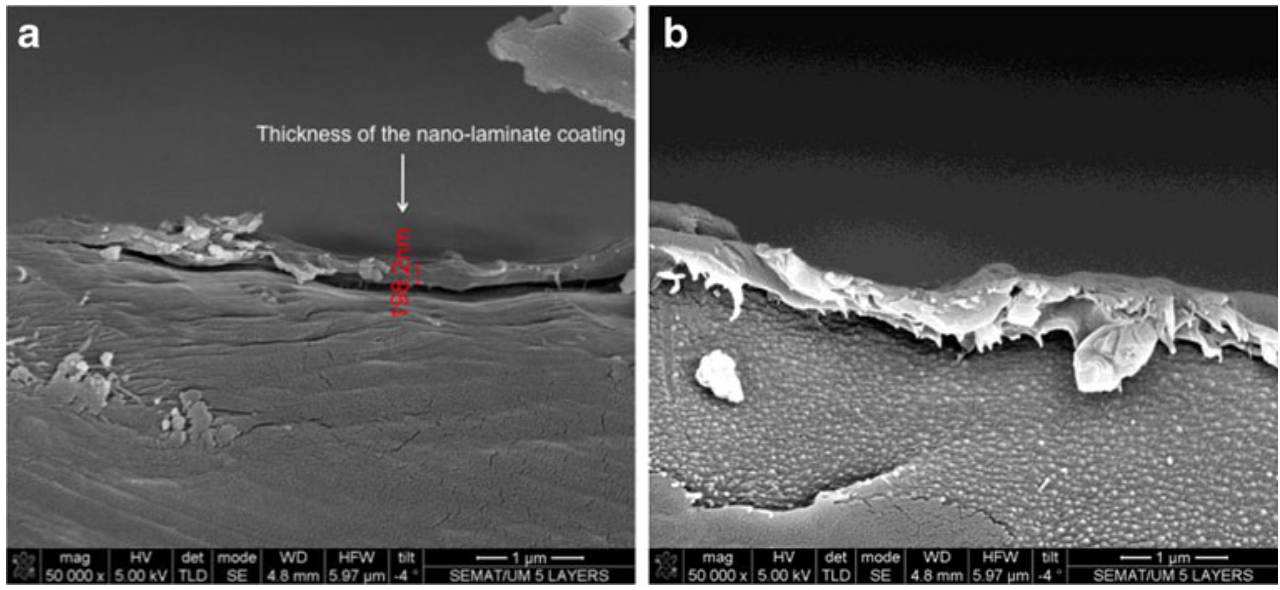

$10^{-5} \mathrm{~g} \mathrm{~m}^{-2} \mathrm{~s}^{-1}$, respectively, which are in agreement with the results obtained by Ohishi (2003) for a PET film.

WVTR value obtained for nano-laminate coating was $1.03 \times 10^{-3} \mathrm{~g} \mathrm{~m}^{-2} \mathrm{~s}^{-1}$; this value is in agreement with the WVTR values obtained by Medeiros et al. (2012b) and Pinheiro et al. (2012), where values of $0.67 \times 10^{-3}$ and $1.37 \times 10^{-3} \mathrm{~g} \mathrm{~m}^{-2} \mathrm{~s}^{-1}$ were reported, respectively. The WVTR value for nano-laminate coatings is lower than the values reported for cellophane films and higher than values obtained for low-density polyethylene (LDPE). When mentioning the lower values of WVTR reported for LDPE in comparison with the nanolaminate coating, it is important to note that the nanolaminate coating presented a thickness lower than $1 \mu \mathrm{m}$, while for LDPE films the thickness values were of ca. $20 \mu \mathrm{m}$.

OTR value obtained for the nano-laminate coating (Eq. 2) was of $1.28 \times 10^{-4} \mathrm{~g} \mathrm{~m}^{-2} \mathrm{~s}^{-1}$, that is higher than the values obtained by Tihminlioglu et al. (2010): $6.86 \times 10^{-7}$ and $3.31 \times 10^{-5} \mathrm{~g} \mathrm{~m}^{-2} \mathrm{~s}^{-1}$ for corn-zein and polypropylene films, respectively. Also, in this case it is important to mention the fact that thickness values of reported films was between 4 and $40 \mu \mathrm{m}$.

Both values of WVTR and OTR of nano-laminate coating are within the range of other reported values. Despite of the nanoscale thickness (198.2 nm, Fig. 3), these values suggest that this coating has selective barrier properties. The polyelectrolyte interactions established between adjacent alginate and lysozyme layers and the hydrophobic amino acid chains of lysozyme contribute to the decrease of the hydrophilicity of the alginate/lysozyme nanocoating. Also, the tortuous pathway possibly formed between alginate and lysozyme layers of the nanocoating decreases its effective permeability to water and oxygen molecules, explaining the obtained results (Medeiros et al. 2012a; Carneiro-da-Cunha et al. 2010; Jang et al. 2008).
Evaluation of Nano-Laminate Coating on Cheese Shelf Life

\section{Physical-Chemical Analyses}

Mass loss can be correlated with water loss of cheese (Olivas and Barbosa-Cánovas 2005). Coated cheese samples presented a lower $(p<0.05)$ mass loss than the uncoated cheese (control) since the 4th until the 20th day (Fig. 4). On 20th day, the mass loss of coated cheese was 1.52-fold lower than that found for uncoated cheese. It was reported that the application of edible coatings, using polysaccharides and/or proteins, decreases the mass loss of cheese; this phenomenon was explained by the barrier to water vapour provided by the coating (Cerqueira et al. 2010; Fajardo et al. 2010; Martins et al. 2010). Martins et al. (2010) found a mass loss 1.6-fold lower for a cheese coated with a galactomannanbased coating when compared with uncoated cheese after 25 days of storage.

Figure 5a shows $\mathrm{pH}$ changes during storage for coated and uncoated cheese samples. For all samples $\mathrm{pH}$ values

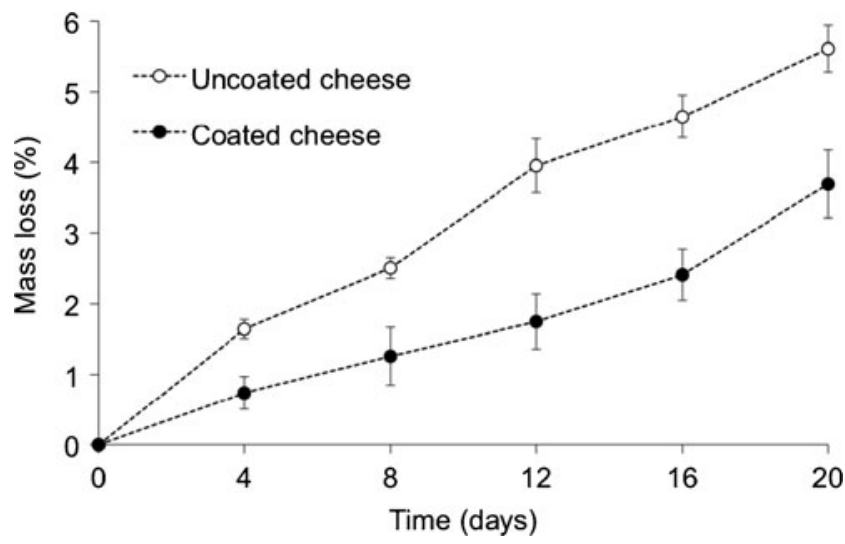

Fig. 4 Mass loss of cheese over the 20 days of storage. Each data point is the average of three determinations and the error bars show the standard deviation 

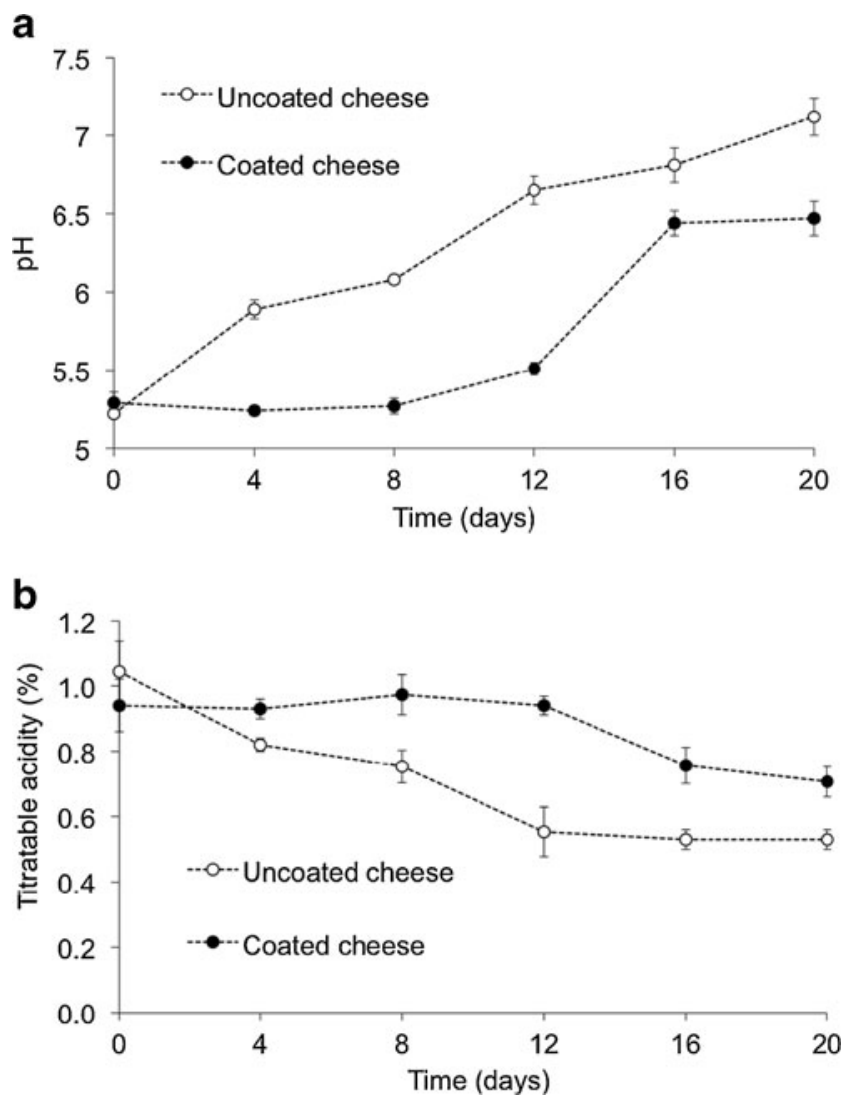

Fig. 5 a pH and b titratable acidity (TA) of coated and uncoated cheese during over the 20 days of storage. Each data point is the average of three determinations and the error bars show the standard deviation

increased, similarly to the behaviour observed by Gutierrez et al. (2004), Laurienzo et al. (2006) and Martins et al. (2010) that obtained an increase of $\mathrm{pH}$ values of cheese during storage. For uncoated cheese the $\mathrm{pH}$ value varied from $5.22 \pm 0$ to $7.12 \pm 0.12$ and for coated cheese from $5.29 \pm 0.07$ to $6.47 \pm 0.11$. This increase can be explained by bacterial protease activity (Grappin et al. 1985). This phenomenon was delayed when the nano-laminate coating was applied on cheese surface. This finding may be explained by the $\mathrm{O}_{2}$ barrier action of alginate/lysozyme nano-laminate coating (as confirmed by OTR values) that caused the decrease of fungal metabolism. Besides, lysozyme antibacterial activity may have influenced the decrease of bacterial proliferation, decreasing the proteolysis and the alkalinisation of cheese (Hughey and Johnson 1987).

Figure $5 \mathrm{~b}$ shows the values of titratable acidity (TA) during storage. TA values decreased in the coated cheese from $0.94 \pm 0.08$ to $0.71 \pm 0.05 \%$ and in uncoated cheese from $1.04 \pm 0.09$ to $0.53 \pm 0.03 \%$. Coated and uncoated cheese showed different $(p<0.05)$ values of TA from the fourth day onwards. Results are in agreement with the values obtained by Ishihara et al. (2009) that found a TA decrease for 'Coalho' cheese from 1.80 to $0.30 \%$ during 30 days of storage.

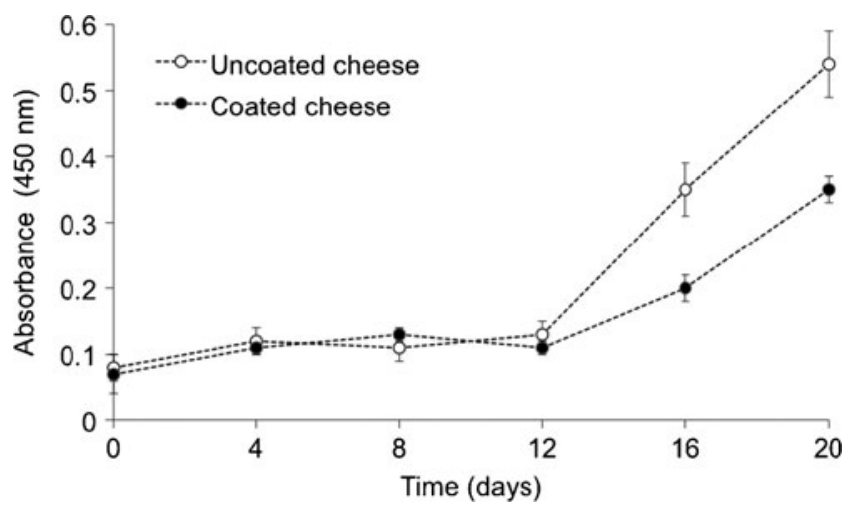

Fig. 6 Lipid oxidation of coated and uncoated cheese during over the 20 days of storage. Each data point is the average of three determinations and the error bars show the standard deviation

Lipid oxidation is one of the worst problems during storage of fatty foods. Oxidative changes can result in off-flavours, destruction of valuable nutrients and production of toxic compounds (Kanner and Rosenthal 1992). Figure 6 shows lipid oxidation over the 20 days of storage. On the first 12 days, a slight increase of absorbance of thiobarbituric acid reactive substances (TBARS) occurred; however only from the 16th day onwards, the values between coated and uncoated cheese are statistically different $(p<0.05)$. At the 20 th day, the values



b

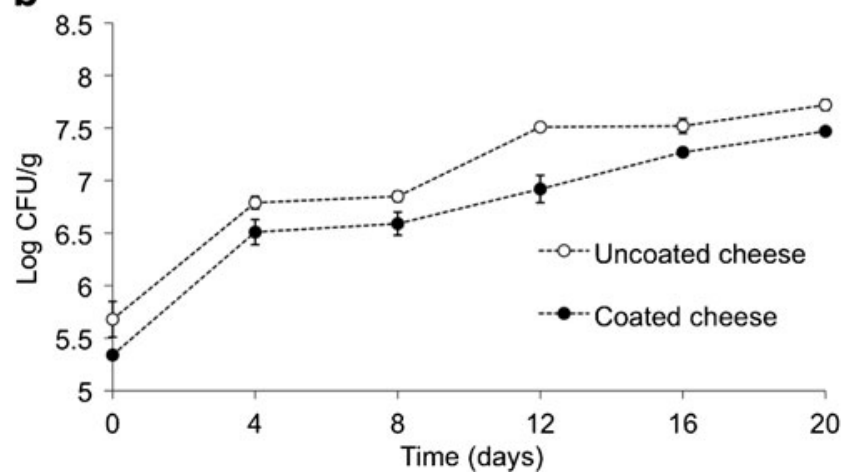

Fig. 7 Microbiological counting of mesophilic (a) and psychotropic (b) microorganisms on cheese over the 20 days of storage. Each data point is the average of three determinations and the error bars show the standard deviation 
(Abs) for uncoated and coated cheese were $0.54 \pm 0.05$ and $0.35 \pm 0.02 \mathrm{~nm}$, respectively. The increase of TBARS values is in agreement with the results obtained by Ye et al. (2009) in processed cheese made with fish oil emulsion. The absorbance increase found in this work is related to the lipid oxidative process of cheese catalysed by transition metals, enzymes and photosensitizers (Mortensen et al. 2004). The lower value of peroxidation in the coated cheese in comparison with uncoated cheese may be attributed to the gas barrier provided by the alginate/lysozyme nanocoating, which contributed to decrease lipid peroxidation. Lipid peroxidation occurs due to a chain reaction led by $\mathrm{O}_{2}$-free radicals in which one radical induces the oxidation of a considerable number of substrate molecules (Fadillioğlu et al. 2003). This process is catalysed by light, and the coating may also act as a barrier to light incidence, further decreasing the lipid oxidation of cheese (Mortensen et al. 2004; Holm et al. 2006).

\section{Microbiological Analyses}

Several works studied the microbiological quality of 'Coalho' cheese and confirmed the presence of spoilage microorganisms (Borges et al. 2003; Santana et al. 2008). Some microorganisms present in cheese are mesophilic and psychrotropic (Borges et al. 2003; Conte et al. 2009).

Figure 7 shows that the increase of mesophilic and psychrotropic microorganisms over storage time was higher $(p<0.05)$ in the uncoated cheese than in the coated cheese. Mesophiles and psychrophiles counts on the uncoated cheese ranged from $6.2 \pm 0.06$ to $8.16 \pm 0.01 \mathrm{log} \mathrm{CFU} / \mathrm{g}$ and from $5.68 \pm 0.17$ to $7.72 \pm 0.05 \mathrm{log} \mathrm{CFU} / \mathrm{g}$, respectively; while in the coated cheese, the values obtained for mesophilic and psychrotrophic bacteria ranged from $6.05 \pm 0.05$ to $7.7 \pm 0.07 \log \mathrm{CFU} / \mathrm{g}$ and from $5.34 \pm 0.04$ to $7.47 \pm 0.02$ $\log \mathrm{CFU} / \mathrm{g}$, respectively. Statistically significant differences $(p<0.05)$ were observed for both mesophilic and psychrotropic counts at the 20th day for uncoated and coated cheese. The decrease of both kinds of microorganisms counts in coated 'Coalho' cheese is possibly related to the antibacterial action of lysozyme that promotes the hydrolization of peptidoglycan causing cell lysis (Masschalck and Michiels 2003) and to the $\mathrm{O}_{2}$ barrier properties of the coating, decreasing $\mathrm{O}_{2}$ transfer rate and making it less available for fungal growth (Cerqueira et al. 2010). Roos et al. (2005) while evaluating the microbiological quality of 'colonial' cheese found counts that ranged from 7.17
Fig. 8 Images of uncoated (a and $\mathbf{c})$ and coated cheese (b and d) captured on the day $0(\mathbf{a}, \mathbf{b})$ and on the 20th day $(\mathbf{c}, \mathbf{d})$ of storage
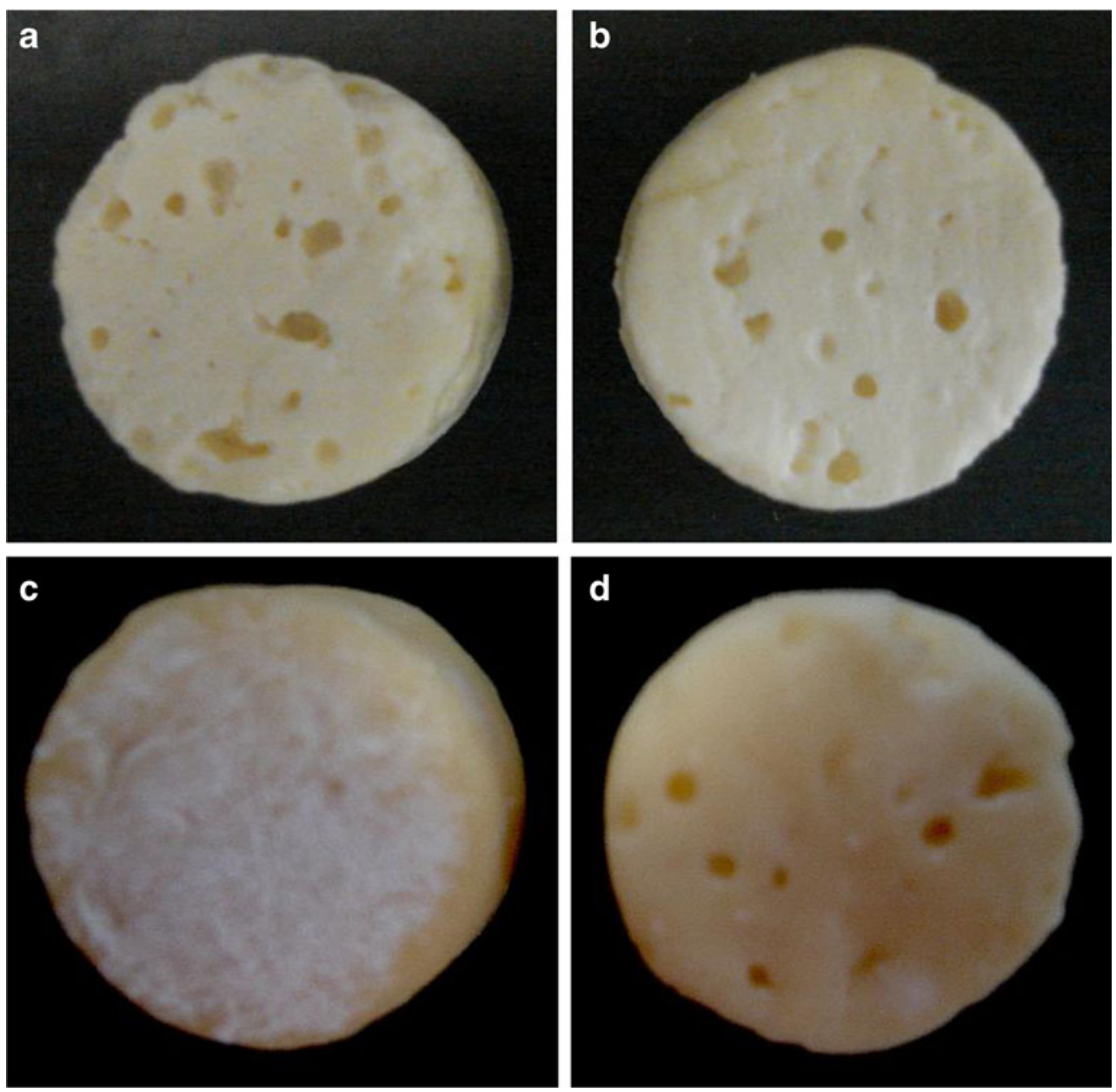
to $10.39 \log \mathrm{CFU} / \mathrm{g}$ for mesophilic microorganisms and from 6.82 to $9.44 \log \mathrm{CFU} / \mathrm{g}$ for psychrotropic microorganisms. Similar results were obtained by Gammariello et al. (2009) that applied modified atmosphere packaging to decrease microbiological contamination in Stracciatella cheese.

\section{Visual Evaluation}

Fungal spoilage of dairy foods causes metabolic alterations, which are responsible for off odours and flavours and a visible change in colour or texture (Loralyn and Robert 2009). Figure 8 shows the images of coated and uncoated cheese taken at the beginning and at the end of storage. It is visible on the surface of uncoated cheese (Fig. 8c), on the 20th day, the proliferation of some microorganisms while the coated cheese (Fig. 8d) is practically without signs of fungal contamination; these observations were confirmed by microbiological analyses. These observations are explained by the presence of the nano-laminate coating, that provokes the lysis of cell walls of gram-positive bacteria due the presence of lysozyme (Ramanauskien et al. 2009) and decreases fungal growth by establishing an oxygen barrier at the surface of the cheese.

In a work carried out by Duan et al. (2007) with chitosanlysozime films and coatings on Mozzarella cheese, microorganisms such as Escherichia coli, Pseudomonas fluorescens, Listeria monocytogenes, Cladosporium spp. and Candida inconspicua were inoculated in cheese samples and microbiological analyses were conducted during 14 and 30 days for bacteria and for fungi, respectively. These authors found a significant growth reduction of bacteria and moulds, being the application of a wrapper film the one that presented better results. They also found that the addition of lysozyme enhanced the antimicrobial effect of films and coatings against $P$. fluorescens and $L$. monocytogenes.

\section{Conclusions}

Alginate and lysozyme nanocoating assembling was confirmed by UV-vis spectroscopy, contact angle, and characterised in terms of gas barrier properties and scanning electron microscopy (SEM) analyses. After that, the same methodology was used for the application of the alginate/lysozyme nanomultilayer coating in 'Coalho' cheese and the shelf life was evaluated during 20 days of storage. Alginate and lysozyme nanocoating presented WVTR and OTR values of $1.03 \times 10^{-3}$ and $1.28 \times 10^{-4} \mathrm{~g} \mathrm{~m}^{-2} \mathrm{~s}^{-1}$, respectively, and after 20 days coated cheese showed lower values of mass loss, $\mathrm{pH}$, lipidic peroxidation, microorganisms' proliferation and higher titratable acidity in comparison with uncoated cheese. The mesophilic and psychrotropic microbial counts and the visual evaluation of fungal contamination were also found to be lower on coated cheese than on uncoated cheese. These results suggest that the combination of gas barrier and antibacterial properties of the coating had a positive effect on physicalchemical parameters of cheese, leading to a shelf life extension. This might be an alternative material for food industry, which takes into consideration the actual safety and environmental requirements for packaging material.

Acknowledgments The author Bartolomeu G. de S. Medeiros is recipient of a scholarship from Coordenação de Aperfeiçoamento de Pessoal de Nivel Superior (CAPES-Brazil). The author Marthyna P. Souza is recipient of a scholarship from Fundação de Amparo à Ciência e Tecnologia do Estado de Pernambuco (FACEPE, Brazil) and was recipient of a scholarship from Coordenação de Aperfeiçoamento de Pessoal de Nivel Superior (CAPES/PDEE-Brazil). The authors Ana C. Pinheiro, Ana I. Bourbon and Miguel A. Cerqueira are recipients of a fellowship (SFRH/BD/48120/2008, SFRH/BD/ $73178 / 2010$ and SFRH/BPD/72753/2010, respectively), supported by Fundação para a Ciência e Tecnologia, POPH-QREN and FSE (FCT, Portugal). Maria G. Carneiro-da-Cunha express is gratitude to the Conselho Nacional de Desenvolvimento Científico e Tecnológico (CNPq) for research grant. The present work was supported by CAPES/PROCAD/NF/1415/2007. The support of EU Cost Action FA0904 is gratefully acknowledged.

\section{References}

ASTM D 3985-02 (2002). Standard test method for oxygen gas transmission rate through plastic film and sheeting using a coulometric sensor. In ASTM Book of Standards, 15.09.

Borges, M. F., Feitosa, T., Nassu, R. T., Muniz, C. R., Azevedo, E. H. F., \& Figueiredo, E. A. T. (2003). Microrganismos patogênicos e indicadores em queijo de coalho produzido no estado do Ceará, Brasil. Boletim do Centro de Pesquisa de Processamento de Alimentos, 2(11), 31-40.

Carneiro-da-Cunha, M. G., Cerqueira, M. A., Souza, B. W. S., Carvalho, S., Quintas, M. A. C., Teixeira, J. A., et al. (2010). Physical and thermal properties of a chitosan/alginate nanolayered PET film. Carbohydrate Polymers, 82(1), 153-159.

Casariego, A., Souza, B. W. S., Cerqueira, M. A., Teixeira, J. A., Cruz, L., Díaz, R., et al. (2009). Chitosan/clay films' properties as affected by biopolymer and clay micro/nanoparticles' concentrations. Food Hydrocolloids, 23(7), 1895-1902.

Cerqueira, M. A., Lima, A. M., Souza, B. W. S., Teixeira, J. A., Moreira, R. A., \& Vicente, A. A. (2009). Functional polysaccharides as edible coatings for cheese. Journal of Agricultural and Food Chemistry, 57, 1456-1462.

Cerqueira, M. A., Sousa-Gallagher, M. J., Macedo, I., RodriguezAguilera, R., Souza, B. W. S., Teixeira, J. A., et al. (2010). Use of galactomannan edible coating application and storage temperature for prolonging shelf-life of "Regional" cheese. Journal of Food Engineering, 97, 87-94.

Conte, A., Gammariello, D., Di Giulio, S., Attanasio, M., \& Del Nobile, M. A. (2009). Active coating and modified-atmosphere packaging to extend the shelf life of Fior di Latte cheese. Journal of Dairy Science, 92, 887-894.

Decher, G. (2003). Polyelectrolyte multilayers, an overview. In G. Decher \& J. B. Schlenoff(Eds.), Multilayer thin films (pp. 1-46). Weinheim: Wiley. 
Duan, J., Park, S.-I., Daeschel, M. A., \& Zhao, Y. (2007). Antimicrobial chitosan-lysozyme (CL) films and coatings for enhancing microbial safety of Mozzarella cheese. Journal of Food Science, 72, M355-M362.

Durmaz, Y. Y., Sangermano, M., \& Yagci, Y. (2010). Surface modification of UV-cured epoxy resins by click chemistry. Journal of Polymer Science: Part A: Polymer Chemistry, 48, 2862-2868.

Fajardo, P., Martins, J. T., Fuciños, C., Pastrana, L., Teixeira, J. A., \& Vicente, A. A. (2010). Evaluation of a chitosan-based edible film as carrier of natamycin to improve the storability of Saloio cheese. Journal of Food Engineering, 101, 349-356.

Fadillioğlu, E., Erdoğan, H., Söğüt, S., \& Kuku, I. (2003). Protective effects of erdosteine against doxorubicin-induced cardiomyopathy in rats. Journal of Applied Toxicology, 23, 71-74.

Food and Agriculture Organization of the United Nations (FAO) (1990). The technology of traditional milk products in developing countries. Section 3. Rome ISBN 92-5-102899-0. http://www.fao.org/docrep/ 003/t0251e/T0251E13.htm. Accessed 7 July 2012.

Fu, J., Ji, J., Yuan, W., \& Shen, J. (2005). Construction of anti-adhesive and antibacterial multilayer films via layer-by-layer assembly of heparin and chitosan. Biomaterials, 26, 6684-6692.

Gammariello, D., Conte, A., Di Giulio, S., Attanasio, M., \& Del Nobile, M. A. (2009). Shelf life of Stracciatella cheese under modifiedatmosphere packaging. Journal of Dairy Science, 92, 483-490.

Grappin, R., Rank, T. C., \& Olson, N. F. (1985). Primary proteolysis of cheese proteins during ripening. A review. Journal of Dairy Science, 68(3), 531-540.

Gutierrez, E. M. R., Domarco, R. E., Spoto, M. H. F., Blumer, L., \& Matraia, C. (2004). Efeito da radiação gama nas características físico-químicas e microbiológicas do queijo prato durante a maturação. Ciência e Tecnologia de Alimentos., 24(4), 596-601.

Harnsilawat, T., Pongsawatmanit, R., \& McClements, D. J. (2006). Characterization of $\beta$-lactoglobulin-sodium alginate interactions in aqueous solutions: a calorimetry, light scattering, electrophoretic mobility and solubility study. Food Hydrocolloids, 20, 577-585.

Hinrichsen, G., Hoffmann, A., Schleeh, T., \& Macht, C. (2003). Continuous production of ultrathin polymeric nanofilms using the spontaneous film formation technique. Advances in Polymer Technology., 22(2), 120-125.

Holm, V. K., Mortensen, G., \& Risbo, J. (2006). Quality changes in semi-hard cheese packaged in a poly(lactic acid) material. Food Chemistry, 97, 401-410.

Hughey, V. L., \& Johnson, E. A. (1987). Antimicrobial activity of lysozyme against bacteria involved in food spoilage and foodborne disease. Applied and Environmental Microbiology., 53(9), 2165-2170.

Ibrahim, H. R., Matsuzaki, T., \& Aoki, T. (2001). Genetic evidence that antibacterial activity of lysozyme is independent of its catalytic function. FEBS Lett., 506, 27-32.

Instituto Adolfo Lutz (1985). Normas analíticas: métodos químicos e físicos para análises de alimentos, 3rd edition v 1.São Paulo, Brazil. p. 533.

Ishihara, R. Y., Pereira, C., \& Porcu, O. M. (2009). Queijo de coalho adicionado de litesse, zinco e vitamina E: parâmetros fisicoquímicos. Paraná: In XVI SICITE - UTFPR.

Jang, W.-S., Rawson, I., \& Grunlan, J. C. (2008). Layer-by-layer assembly of thin film oxygen barrier. Thin Solid Films, 516(15), 4819-4826.

Jiang, B., \& Li, B. (2009). Tunable drug loading and release from polypeptide multilayer nanofilms. International Journal of Nanomedicine, 4, 37-53.

Kanner, J., \& Rosenthal, I. (1992). An assessment of lipid oxidation in foods. (Technical report). International Union of Pure and Applied Chemistry, 64(12), 1959-1964.

Kristensen, D., Leif, H., \& Skibsted, L. H. (1999). Comparison of three methods based on electron spin resonance spectrometry for evaluation of oxidative stability of processed cheese. Journal of Agricultural and Food Chemistry, 47(8), 3099-3104.

Laurienzo, P., Malinconico, M., Pizzano, R., Manzo, C., Piciocchi, N., Sorrentin, A., et al. (2006). Natural polysaccharide-based gels for dairy food preservation. Journal of Dairy Science, 89, 28562864.

Loralyn, H. L., \& Robert, T. M. (2009). Microbiological spoilage of dairy products. compendium of the microbiological spoilage of foods and beverages. Food Microbiology and Food Safety, 41-67.

Lvov, Y., Ariga, K., Ichinose, I., \& Kunitake, T. (1995). Assembly multicomponent protein films by means of electrostatic layer-bylayer adsorption. Journal of American Chemical Society, 117, 6117-6123.

Martins, J. T., Cerqueira, M. A., Souza, W. S., Avides, M., \& Vicente, A. A. (2010). Shelf life extension of ricotta cheese using coating of galactomannans from nonconventional sources incorporating nisin against Listeria monocytogenes. Journal of Agricultural and Food Chemistry, 58, 1884-1891.

Masschalck, B., \& Michiels, C. W. (2003). Antimicrobial properties of lysozyme in relation to foodborne vegetative bacteria. Critical Reviews in Microbiology, 29(3), 191-214.

Medeiros, B. G. d. S., Pinheiro, A. C., Carneiro-da-Cunha, M. G., \& Vicente, A. A. (2012). Development and characterization of a nanomultilayer coating of pectin and chitosan - evaluation of its gas barrier properties and application on 'Tommy Atkins' mangoes. Journal of Food Engineering, 110, 457-464.

Medeiros, B. G. d. S., Pinheiro, A. C., Teixeira, J. A., Vicente, A. A., \& Carneiro-da-Cunha, M. G. (2012). Polysaccharide/protein nanomultilayer coatings: construction, characterization and evaluation of their effect on 'Rocha' pear (Pyrus communis L.) shelf-life. Food and Bioprocess Technology, 5, 2435-2445.

Mortensen, G., Bertelsen, G., Mortensen, B. K., \& Stapelfeldt, H. (2004). Light-induced changes in packaged cheeses - a review. International Dairy Journal, 14(2), 85-102.

Neethirajan, S., \& Jayas, D. (2011). Nanotechnology for the food and bioprocessing industries. Food and Bioprocess Technology, 4(1), 39-47.

Newman, A. W., \& Kwok, D. Y. (1999). Contact angle measurement and contact angle interpretation. Advances in Colloid andInterface Science, 81, 167-249.

NP 4405. (2002). Food microbiology-general guidance for the enumeration of micro-organisms, colony count technique at $30{ }^{\circ} \mathrm{C}$. Lisbon: IPQ

Nussinovitch, A., \& Kampf, N. (2000). Hydrocolloid coating of cheeses. Food Hydrocolloids, 14, 531-537.

Ohishi, T. (2003). Gas barrier characteristics of a polysilazane film formed on an ITO-coated PET substrate. Journal of NonCrystalline Solids, 330, 248-251.

Olivas, G. I., \& Barbosa-Cánovas, G. V. (2005). Edible coatings for fresh-cut fruits. Critical Reviews in Food Science and Nutrition, 45, 657-670.

Peng, J. B., Barnes, G. T., \& Gentle, I. R. (2001). The structures of langmuir-blodgett films of fatty acids and their salts. Advances in Colloid and Interface Science, 91, 163-219.

Perry, K. S. P. (2004). Queijos: aspectos químicos, bioquímicos e microbiológicos. Quimica Nova, 27, 293-300.

Pinheiro, A. C., Medeiros, B. G. d. S., Carneiro-da-Cunha, M. G., \& Vicente, A. A. (2012). Interactions between K-carrageenan and chitosan in nanolayered coatings - structural and transport properties. Carbohydrate Polymers, 87(2), 1081-1090.

Ministério da Agricultura (1996) Portaria no ${ }^{\circ}$ 146, de 7 de março de 1996. Regulamento técnico de identidade e qualidade de queijos. Diário Oficial da República Federativa do Brasil, Brasília, DF, 11 mar. 1996, Seção 1, 3977-3978. Brasil.

Ramanauskien, K., Inkeniene, A. M., Savickas, A., Masteikova, R., \& Brusokas, V. (2009). Analysis of the antimicrobial 
activity of propolis and lysozyme in semisolid emulsion systems. Acta Poloniae Pharmaceutica in Drug Research, 66(6), 681-688.

Rhim, J. W., Hong, S. I., Park, H. M., \& Perry, K. W. N. (2006). Preparation and characterization of chitosan-based nanocomposite films with antimicrobial activity. Journal of Agricultural and Food Chemistry, 54, 5814-5822.

Roos, T.B., Scheid Filho, V. B., Timm, C.D., \& Oliveira, D.S. (2005). Avaliação microbiológica de queijo colonial produzido na cidade de Três Passos.Revista Higiene Alimentar, São Paulo, v. 19, n. 132, p. 94-96, 2005.

Saether, H. V., Holme, H. K., Maurstad, G., Smidsrød, O., \& Stokke, B. T. (2008). Polyelectrolyte complex formation using alginate and chitosan. Carbohydrate Polymers, 74, 813-821.

Santana, R. F., Santos, D. M., Martinez, A. C. C., \& Lima, A. S. (2008). Qualidade microbiológica de queijo-coalho comercializado em aracaju, SE. Arquivo Brasileiro de Medicina Veterinária e Zootecnia, 60(6), 1517-1522.

Saravanan, M., \& Rao, K. P. (2010). Pectin-gelatin and alginate-gelatin complex coacervation for controlled drug delivery: influence of anionic polysaccharides and drugs being encapsulated on physicochemical properties of microcapsules. Carbohydrate Polymers, $80(3), 808-816$
Satishkumar, R., \& Vertegel, A. (2008). Charge-directed targeting of antimicrobial protein-nanoparticle conjugates. Biotechnology and Bioengineering, 100(3), 403-412.

Su, T. J., Lu, J. R., Thomas, R. K., Cui, Z. F., \& Penfold, J. (1998). The effect of solution $\mathrm{pH}$ on the structure of lysozyme layers adsorbed at the silica-water interface studied by neutron reflection. Langmuir, 14, 438-445.

Tihminlioglu, F., Atik, I. D., \& Özen, B. (2010). Water vapor and oxygen-barrier performance of corn-zein coated polypropylene films. Journal of Food Engineering, 96, 342-347.

Wang, X., Xiao, H., Daley, A., Rabotyagova, O., Peggy, C., \& Kapplan, D. L. (2007). Nanolayer biomaterial coatings of silk fibroin for controlled release. Journal of Controlled release, 121, 190-199.

Ye, A., Cui, J., Taneja, A., Zhu, X., \& Singh, H. (2009). Evaluation of processed cheese fortified with fish oil emulsion. Food Research International, 42(8), 1093-1098.

Zazouli, M. A., Ulbricht, M. U., Nasseri, S., \& Susanto, H. (2010). Effect of hydrophilic and hydrophobiic organic matter on amoxicillin and cephalexin residuals rejection from water by nanofiltration. Iranian Journal of Environmental Health Science \& Engineering, 7, 15-24.

Zhong, Y., Whittington, C. F., \& Haynie, D. T. (2007). Stimulated release of small molecules from polyelectrolyte multilayer nanocoatings. Chemical Communications, 14, 1415-1417. 